RHiNOLOGY

\title{
Extracorporeal septoplasty with internal nasal valve stabilisation
}

\author{
La chirurgia extracorporea del setto nasale \\ con stabilizzazione della valvola nasale interna
}

\author{
I. Tasca', G. Ceroni Compadretti', T. I. Losano², Y. Lijdens², C. Boccio² \\ ${ }^{1}$ Department Othorhinolaryngology, Imola Hospital, Italy; ${ }^{2}$ ENT Department, Italian Hospital, Buenos Aires, Argentina
}

\section{SUMMARY}

Among various septoplasty techniques, the extracorporeal one is used for severe deformities of the caudal septum and consists essentially in removal of the nasal septum followed by correction of deformities. Reconstruction of the neo-septum is carried out by repositioning the septal fragments in a straight position. The disadvantages of this surgical technique are the septal haematoma, oedema of the mucosa in the valve area and some types of abnormalities of the middle third of the nose such as saddling of the dorsum. All of these conditions can be associated with various degrees of functional disorders. To prevent these possible complications, we developed a suture technique to fix the caudal portion of the neo-septum and avoid alterations or narrowing of the internal nasal valve. The purpose of this study is to describe extracorporeal septoplasty results with this suture technique in stabilising the internal nasal valve. From January 2011 to December 2013, a retrospective review of adult patients treated with extracorporeal septoplasty was performed at the ENT department of Imola Hospital. Pre- and post-operative evaluations were carried out by rhinomanometry and acoustic rhinometry. Statistical analysis was performed with commercially available software (IBM SPSS Statistics for Windows, Version 21.0. Armonk, NY: IBM Corp). 133 cases fulfilled inclusion criteria and were enrolled. A significant improvement was evident after surgery based on the results of rhinomanometry and acoustic rhinology. Extracorporeal septoplasty with stabilisation of the internal nasal valve is an effective and reproducible surgical technique that yields optimal functional results.

KEY WORDS: Extracorporeal septoplasty $\bullet$ Suture $\bullet$ Deviated septum $\bullet$ Nasal valve $\bullet$ Results

\section{RIASSUNTO}

Tra le diverse tecniche di settoplastica, quella extracorporea viene utilizzata per le gravi deformità del setto anteriore e consiste essenzialmente nella rimozione del setto nasale, nella correzione delle deformità e nella ricostruzione settale che viene attuata con il riposizionamento dei frammenti settali nella sede corretta. Gli inconvenienti di questa tecnica chirurgica sono l'ematoma settale, l'edema della mucosa nella zona della valvola e la comparsa di alterazioni del terzo medio del naso quali insellamenti del dorso. Tutte queste condizioni si possono associare a vario grado di disturbi funzionali. Per evitare queste possibili complicanze abbiamo sviluppato una particolare tecnica di sutura per fissare la porzione caudale del neosetto ed evitare alterazioni o restringimenti della valvola nasale interna. Lo scopo di questo studio è descrivere $i$ nostri risultati nella settoplastica extracorporea con una tecnica di sutura per la stabilizzazione della valvola nasale interna. Da gennaio 2011 a dicembre 2013 è stata effettuata presso l'Unità Operativa di Otorinolaringoiatria dell'Ospedale di Imola una revisione retrospettiva di pazienti adulti trattati con settoplastica extracorporea. Le valutazioni pre- e post-operatorie sono state eseguite con l'utilizzo della rinomanometria e della rinometria acustica. L'analisi statistica è stata prodotta con il software IBM SPSS Statistics per Windows, versione 21.0 Armonk, NY: IBM Corp. 133 pazienti sono rientrati nei criteri di inclusione e sono stati pertanto reclutati per questo studio. Un miglioramento statisticamente significativo è stato evidente dopo l'intervento chirurgico sulla base dei risultati di rinomanometria e rinometria acustica. La settoplastica extracorporea con stabilizzazione della valvola nasale interna è una tecnica chirurgica efficace e riproducibile che si accompagna a risultati funzionali ottimali.

PAROLE CHIAVE: Chirurgia extracorporea del setto $\bullet$ Sutura $\bullet$ Deviazione del setto nasale $\bullet$ Valvola nasale $\bullet$ Risultati

Acta Otorhinolaryngol Ital 2018;38:331-337

\section{Introduction}

Nasal septal deviation is a common disorder in otolaryngology and one of the major causes of nasal obstruction. In some cases, septal deviation is non-symptomatic, but in a high number of patients it causes functional disturbance. The degree of septal deviation affects the severity of symptoms so that severe nasal obstruction strongly affects the quality of life. In patients with mild or moderate deviation of the septum, traditional techniques of septoplasty are ef- 
fective to improve nasal breathing. On the other hand, in severe anterior deformities, usually associated with stenosis of the nasal valve, these methods have unsatisfying results and can sometimes cause functional problems due to over resection or over weakening of the cartilage ${ }^{1-3}$. In case of severe anterior deformities of the septum, removal of the whole septum, followed by extracorporeal reconstruction and reinsertion, is recommended ${ }^{4-6}$. This technique can be carried out using an open or a close approach. Hence, extracorporeal septoplasty has been demonstrated to be effective in correcting obstructive deviation of anterior nasal septum involving the internal nasal valve. The main drawback of this procedure is destabilisation of the junction of the quadrilateral cartilage and nasal bones with consequent alteration of the dorsal contour and functional impairment of the internal nasal valve. To minimise these events, we developed a modified technique. The purpose of this study is to evaluate outcomes of this modified extracorporeal septoplasty in long-term follow up. Additionally, we report the average operative time for extracorporeal septoplasty, which has not yet been investigated in the international literature to date.

\section{Materials and methods}

Between January 2011 and December 2013, we retrospectively reviewed the medical records of all patients treated by extracorporeal septoplasty in the ENT department of Imola Hospital, Italy. The Institutional Review Board of the Hospital approved this retrospective study. Written informed consent for the procedure was obtained from all patients. We included cases of adult patients suffering from a structural or mixed nasal patency impairment. Information regarding perioperative data including patient demographics, preoperative data, side of the nasal patency impairment, diagnostic studies, operative details, postoperative outcomes and complications was obtained. The side of the nasal obstruction was determined by anterior rhinoscopy and nasal endoscopy. Nasal patency was assessed using anterior active rhinomanometry (AAR) with a Rhinopocket ${ }^{\circledR}$ rhinomanometer and acoustic rhinometry (AR). We performed both examinations before surgery and after during the follow-up period, based on the Consensus report on acoustic rhinometry and rhinomanometry ${ }^{7}$. According to our clinical protocol, we considered a mean total resistance of $0.24 \mathrm{~Pa} / \mathrm{cm}^{3} / \mathrm{s}$ with a range of $0.12-0.52 \mathrm{~Pa} /$ $\mathrm{cm}^{3} / \mathrm{s}$ a normal rhinomanometric result. Resistance is determined at a pressure of $150 \mathrm{~Pa}$. Data was acquired at a flow/pressure display. The AR software provides minimal cross-sectional areas in two separate points: the first minimal cross-sectional area (MCA 1) from $10 \mathrm{~mm}$ to $32 \mathrm{~mm}$ of the nostril, and the second minimal crosssectional area (MCA 2) which is located from $32 \mathrm{~mm}$ to $64 \mathrm{~mm}$ of the nostril. A median MCA 1 value of $0.73 \mathrm{~cm}^{2}$ (range $0.57-1.45 \mathrm{~cm}^{2}$ ) was considered a normal result ${ }^{7}$. Preoperatively, AAR and AR were performed in basal conditions after decongestion and dilatation ${ }^{89}$. Surgical outcomes were evaluated by comparing pre- and postoperative baseline results taking into consideration the last follow-up. We carried out rhinomanometric, acoustic rhinometric and clinical controls at 3,6 and 12 months after surgical intervention. All examinations were done by the same operator after a 15-minute period of acclimatisation.

\section{Surgical technique}

All procedures are performed using an endonasal approach under general anaesthesia and oro-tracheal intubation. All patients underwent an extracorporeal septoplasty procedure. In particular, the entire quadrangular cartilage was surgically removed leaving only a small $3 \mathrm{~mm}$ strip of cartilage close to the keystone area (Fig. 1). Once the septal bony structures were removed, nasal packing was inserted. Packing keeps the crushed bone and/or cartilage fragments repositioned during posterior reconstruction. Reconstruction prevent from dystrophic sequelae which may in turn lead to a flaccid septum and even to a possible septal perforation or prolapse of the turbinates. The most regular, defect-free area of the quadrangular cartilage (which was previously removed) is trimmed and shaped into a rectangle; in some cases, this may include part of the perpendicular plate. The graft is tethered to the muco-pericondral flap with polyglactin 910 suture 3-0 $\left(\right.$ Vycril $\left.^{\circledR}\right)$ (Fig. 2).

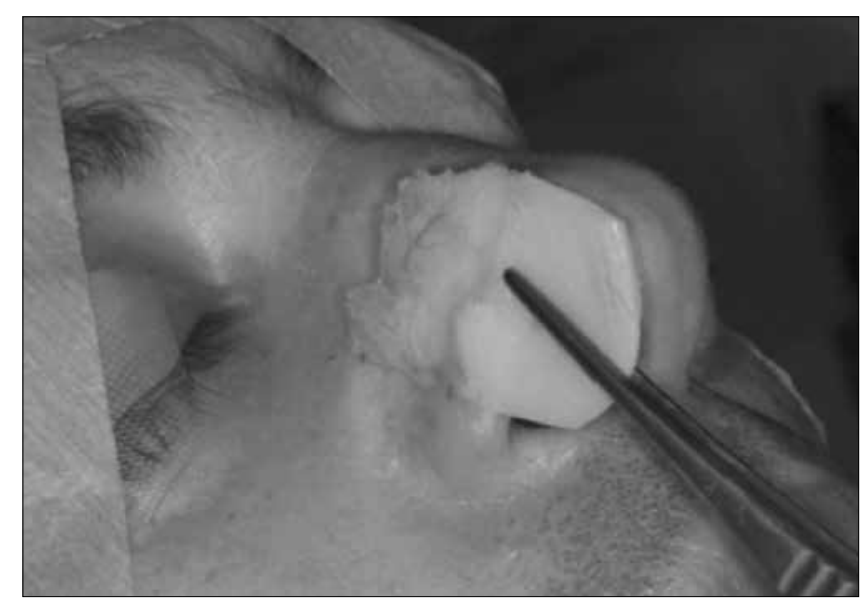

Fig. 1. Quadrangular cartilage with ethmoid bone. 


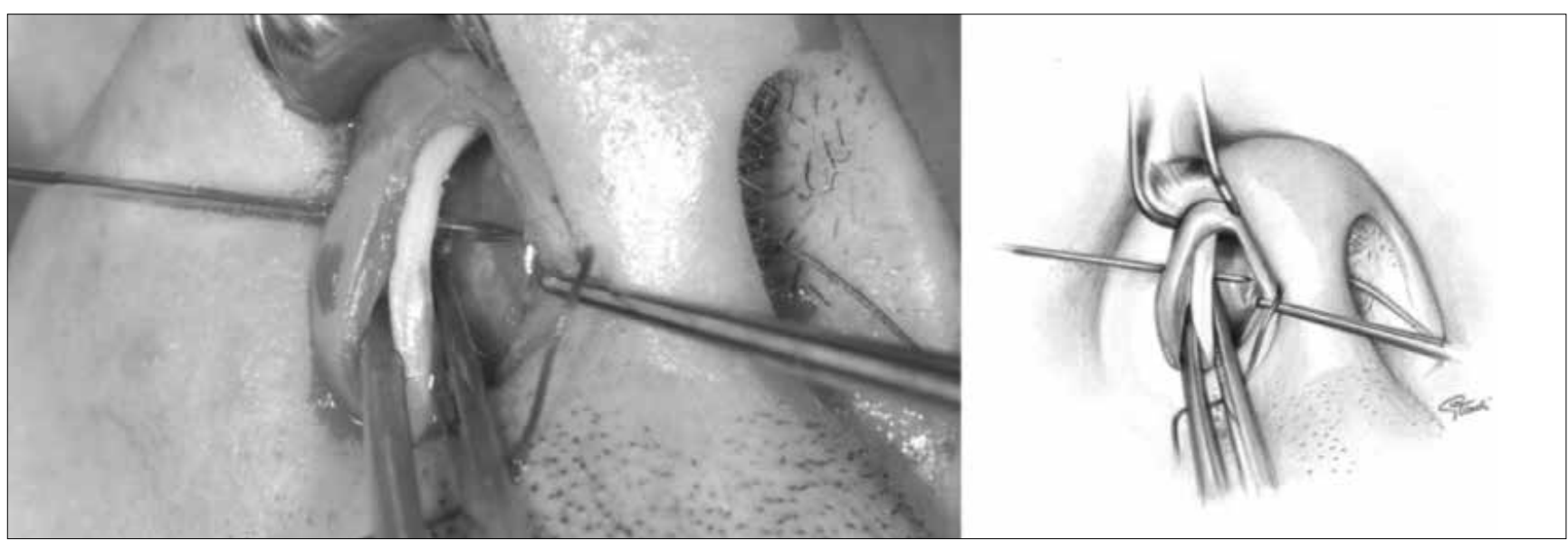

Fig. 2. Graft tethered to the muco-pericondral flap.

\section{Nasal valve stabilisation}

A transfixed suture should be performed under the replaced quadrangular cartilage to give support to the inserted graft in order to prevent the development of saddling deformity (Fig. 3). The graft is also secured to the membranous septum and cartilaginous vault to support and sta- bilise the valve area and to support the naso-labial junction. The hemitransfixion incision is then closed, suturing the septum and columella with transfixed sutures. Closure of the hemitransfixion incision is performed using 3-0 Vicryl suture with a $6 \mathrm{~cm}$ straight needle. Synthetic packing is left in the nasal fossae for 2 days to ensure the

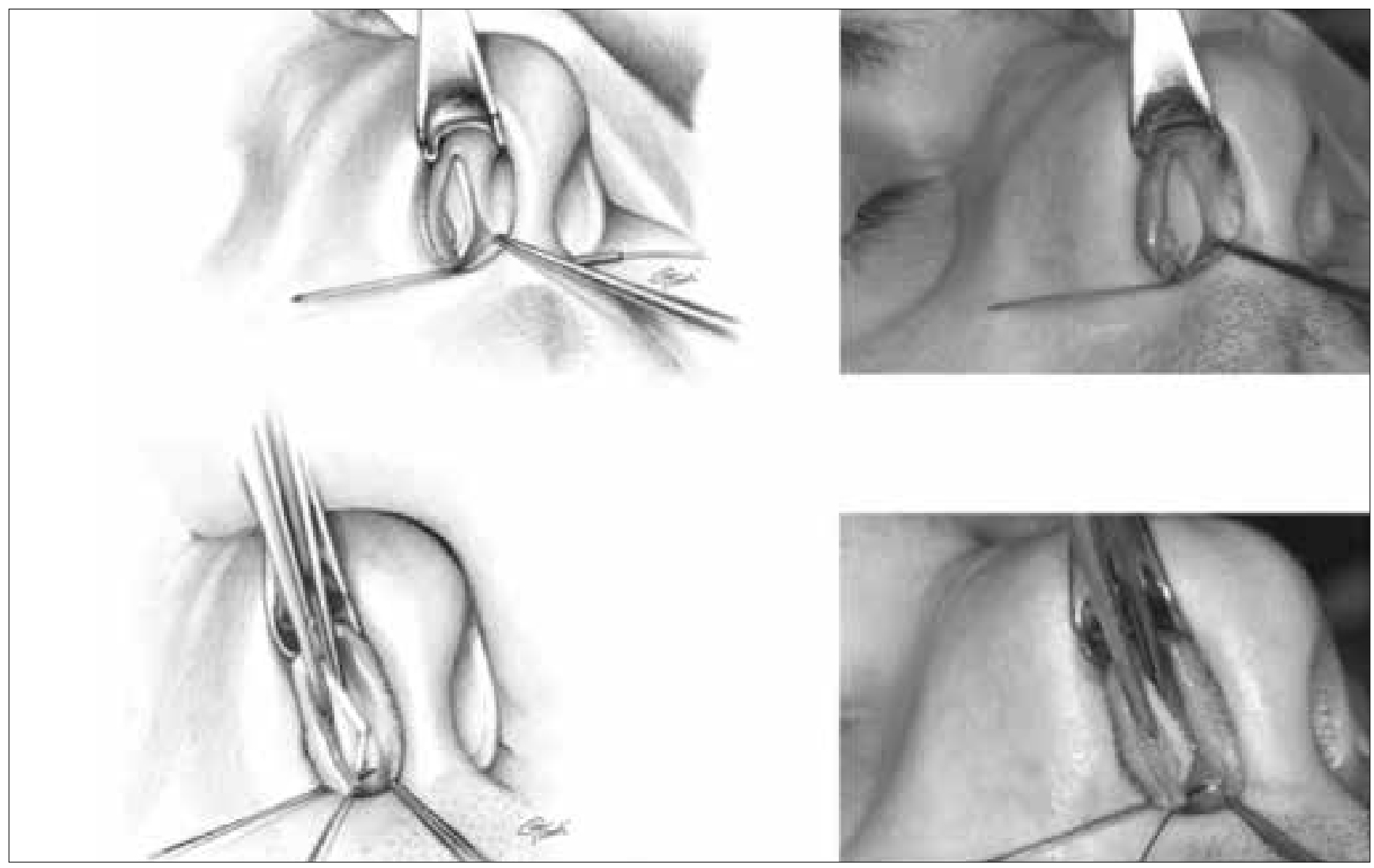

Fig. 3. Suture inserted under the quadrangular cartilage. 
flap adheres, and prevent septal haematoma and displacement of the inserted fragments. This is accomplished by an L-inverted shaped caudo-cranial and antero-posterior suture (Figs. 4, 5). If saddling of the dorsum still persists at the end of the reconstruction procedure, the profile should be normalised by inserting crushed septal cartilage into a dorsal tunnel created through the hemitransfixion incision ${ }^{10}$.

\section{Statistical analysis}

All data were collected using a commercially available database programme $\left(\right.$ Excel $^{\circledR}$ 2013; Microsoft ${ }^{\circledR}$, Redmond, WA, US). The unit of analysis was each patient before and after surgery. In the descriptive analysis, quantitative variables with normal distribution were expressed with means and standard deviation and the ones with abnormal distribution with medians and range; qualitative categorical variables were summarised as frequency and percentage. Preoperative nasal resistance obtained by AAR and nasal cross sectional areas obtained by AR were compared with postoperative results using the non-parametric Wilcoxon
Sign Rank test. Differences were considered significant at a $\mathrm{p}$ value $<0.05$. Statistical analysis was performed with commercially available software (IBM SPSS Statistics for Windows, Version 21.0. Armonk, NY: IBM Corp).

\section{Results}

Among adult patients treated with extracorporeal septoplasty from January 2011 to December 2013, 133 cases fulfilled inclusion criteria for the purposes of the study. Patient characteristics are summarised in Table I. Surgeries were done by five different surgeons of the ENT department with a median operating time of 42 minutes (range, 20-58). No intraoperative complications were reported. All patients were hospitalised for 48 hours. Early complications included septal haematoma in one patient $(0.75 \%)$ that required drainage in the outpatient clinic. Mean follow-up was 12 months (SD, 6.3). Three patients (2.25\%) had to be re-operated on due to impaired nasal patency. A significant improvement was evident after surgery based on rhinomanometric and acoustic rhinometric outcomes (Table II).

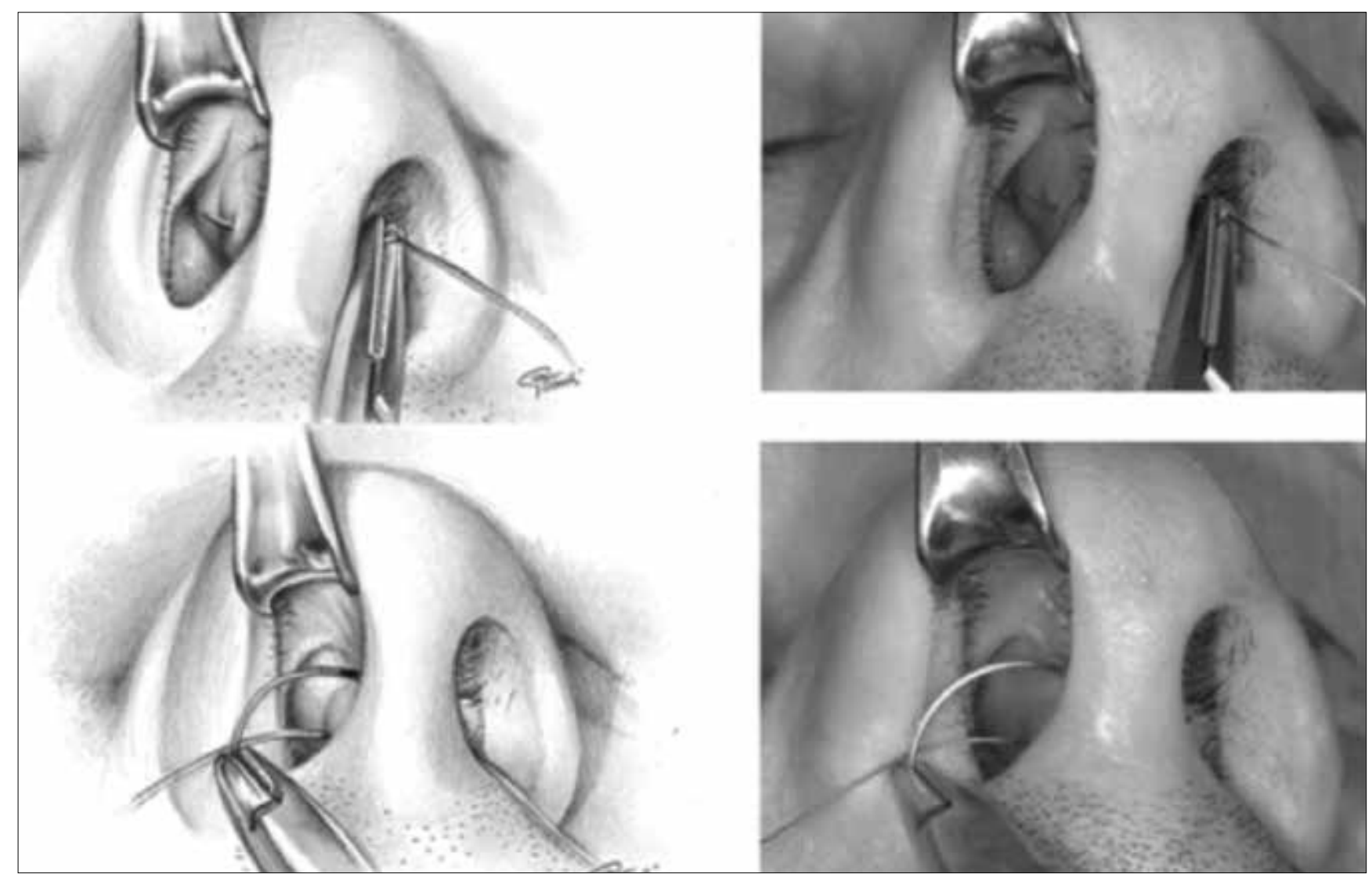

Fig. 4. Vertical mattress suture to stabilise the valve area. 


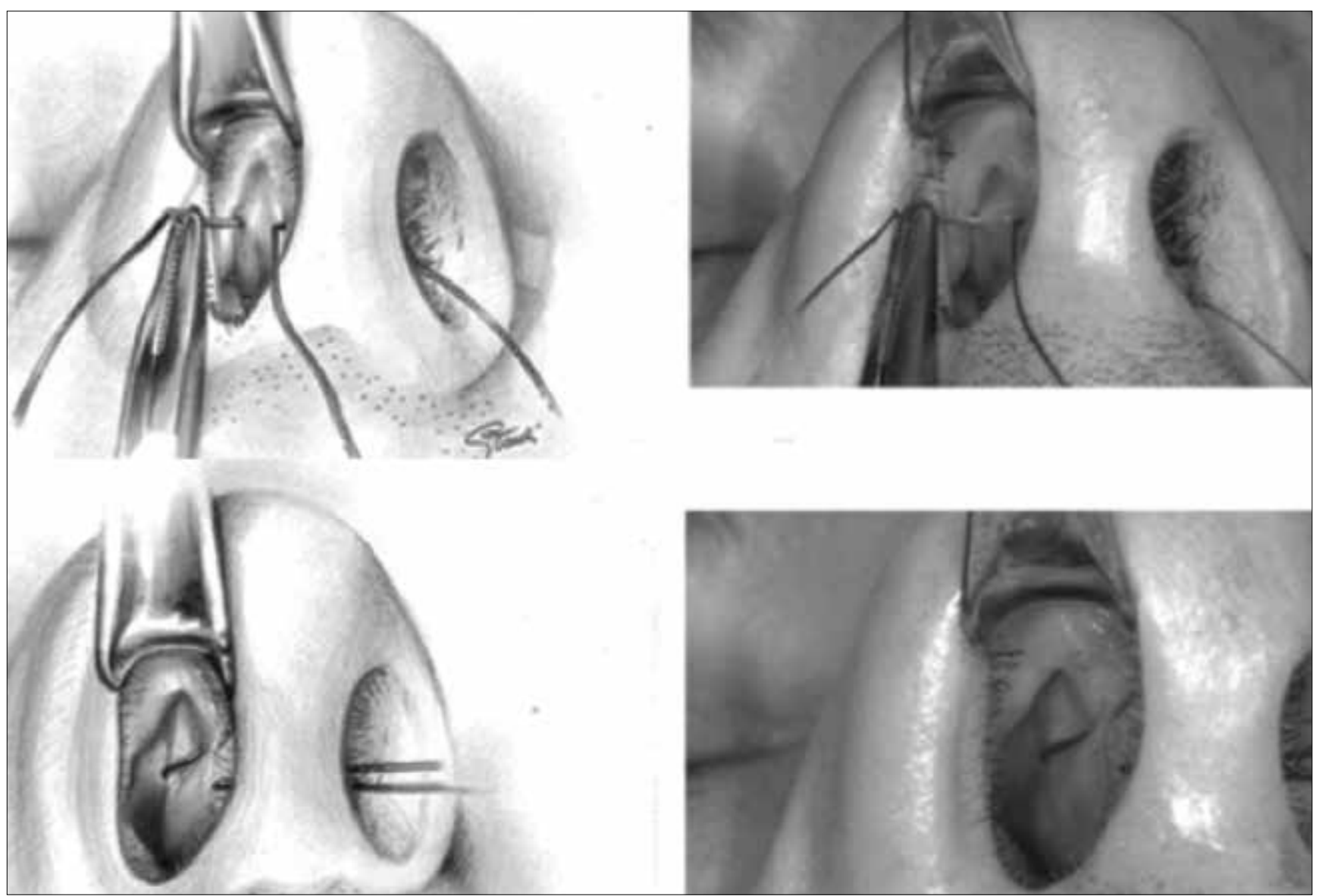

Fig. 5. Horizontal mattress suture to stabilise the valve area.

\section{Discussion}

Septoplasty is the most common procedure performed in rhinology. Ever since Killian and Freer introduced the concept of submucous resection, the technique has been gradually developed by many operators sustainably and

Table I. Patient characteristics.

\begin{tabular}{lc} 
Variable & $\mathbf{N}=133$ \\
Male, $\mathrm{n}(\%)$ & $109(82)$ \\
Age, mean (SD), years & $41.76(15)$ \\
Previously treated, $\mathrm{n}(\%)$ & $27(20.3)$ \\
Side affected, $\mathrm{n}(\%)$ & \\
$\quad$ Right nostril & $37(27.8)$ \\
$\quad$ Left nostril & $46(34.6)$ \\
$\quad$ Bilateral & $50(37.6)$ \\
Type of rhinomanometric impairment $\mathrm{n}(\%)$ & \\
$\quad$ Structural & $41(30.82)$ \\
$\quad$ Mixed & $92(69.7)$ \\
\hline
\end{tabular}

scientifically. In the last century, there have been significant advances in surgical septal procedures. The methods of approaching the caudal nasal septum are cartilage reshaping procedures and septal reconstruction manoeuvres. Modern septal surgery was developed in the 1950s by Cottle ${ }^{11}$. For decades, the maxilla-premaxilla approach has been the workhorse for nose surgeons; limitations of this technique include extreme anterior or superior septal deviations and complex deviations due to multiple fracture lines or lack of cartilage. Nowadays there is no standard treatment for all types of deformities. Techniques such as suture, swinging door, septal batten, ethmoid bone sandwich graft, tongue-in-groove and extracorporeal septoplasty have been used in managing caudal septal deviation ${ }^{1-6}$. This broad range of approaches illustrates the difficulty in treating caudal septal deviation and this is the reason why we consider that there is no doubt regarding the need to obtain pre- and post-operative rhinometric measures if objective results in septal surgery are to be achieved. Extracorporeal septoplasty with the described suture technique has several advantages over other correc- 
Table II. Comparative pre-operative and post-operative baseline investigation results.

\begin{tabular}{lccc} 
Variable & Pre-operative & Post-operative & $\mathbf{p}$ \\
$\begin{array}{l}\text { AAR Pa/cm } / \mathrm{s} \\
\text { median (range) }\end{array}$ & & & \\
$\begin{array}{l}\text { Baseline right nostril } \\
\quad \text { Inspiration }\end{array}$ & $0.74(0.00-61.00)$ & $0.27(0.00-1.77)$ & 0.000 \\
$\quad$ Expiration & $0.61(0.00-28.40)$ & $0.00(0.00-1.29)$ & 0.000 \\
Baseline left nostril & & & \\
$\quad$ Inspiration & $1.14(0.00-240.00)$ & $0.26(0.00-2.44)$ & 0.000 \\
$\quad$ Expiration & $1.00(0.00-553.0)$ & $0.00(0.00-1.75)$ & 0.000 \\
AR cm ${ }^{2}$ & & & \\
median (range) & & & \\
Baseline right nostril & & & \\
MCA 1 & $0.32(0.08-0.96)$ & $0.44(0.16-2.08)$ & 0.000 \\
MCA 2 & $0.31(0.03-1.11)$ & $0.50(0.14-1.13)$ & 0.000 \\
Baseline left nostril & & & \\
MCA 1 & $0.32(0.05-0.87)$ & $0.38(0.09-1.94)$ & 0.002 \\
MCA 2 & $0.28(0.04-0.96)$ & $0.41(0.13-0.93)$ & 0.000 \\
\hline
\end{tabular}

tive techniques for caudal septal deviation. In case of suboptimal results, conservative remodelling of the quadrangular cartilage and respect of the majority of cartilaginous structures can be useful for grafting during secondary or revision rhinoseptoplasty. An immediate intra-operative check-up of the straightening of the caudal septum is possible with low risk of deviation recurrence. In fact, this technique completely avoids the cartilage memory from bending, which is a major issue because cartilage has a strong tendency to return to its original shape.

The operative time that we measured in the study is also a strong point. Hardy et al. ${ }^{12}$ in a cohort of 1753 patients who underwent a broad range of complex plastic surgical procedures concluded that surgical duration is an independent predictor of complications, with a significantly increased risk after 3 hours. Septoplasty is usually associated with other surgical procedures such as functional endoscopic sinus surgery and rhinoplasty. For this reason we consider it important to measure surgical time, to organise the surgical schedule and operative time when the intervention is associated with other procedures.

The drawbacks of this procedure are swelling of the mucosa, restenosis of the nasal valve area, septal haematoma and saddle nose development. They can be avoided by correct suture technique to straight the mucosa, especially in the valve area and give support to the repositioned cartilage and prevent saddle nose development. This purpose can be achieved when a sufficient amount of septal cartilage is available for reconstruction such as in primary septoplasty. In case of revision surgery, we are used to positioning the silicone splints into nasal cavities, leaving them for at least 15 days to maintain the septum in a straight position. When there is a shortage of cartilage, we reinforce the neo-septum using calvarian cartilage grafts. In these particular situations, we also consider the use of internal nasal valve reconstruction techniques such as butterfly graft, flaring suture techniques, spreader grafts and Gassner type graft ${ }^{13-16}$. These techniques include the interruption of the T-bar or septal- triangular unit and the use of grafts. Grafts are somewhat intended for partial reabsorption, are at risk for potential destabilization and accompany a donor site morbidity. For all these reasons, we prefer not to use these techniques in primary surgery cases.

\section{Conclusions}

The extracorporeal septoplasty technique is a successful surgical technique for anterior deviations of the septum. We emphasise that the replacement of removed cartilage with the described suture technique is an important step in the surgery that must be taken into consideration to get good functional and aesthetic results. Extracorporeal septal reconstruction is the advocated procedure for correction of a markedly deviated nasal septum. The technique has been demonstrated to be safe and effective in restoring nasal patency and the results remain stable during long-term follow-up. Some variants of the classic procedure may be useful to stabilise the reconstructed septum, above all in the valve angle, and preserve structured support of the nasal archway to avoid nasal dorsal irregularity or collapse of the mid-nasal vault.

\section{References}

1 Metzenbaum M. Replacement of the lower end of the dislocated septal cartilage versus submucous resection of the dislocated end of the septal cartilage. Arch Otolaryngol 1929;9:282-96.

2 Killian G. The submucosus window resection of the nasal septum. Ann Otorhinolaryng 1905;14:363.

3 Ellis MS. Suture technique for caudal septal deviations. Laryngoscope 1980;90:1510-2.

4 Gubisch W. The extracorporeal septum plasty: a technique to correct difficult nasal deformities. Plast Reconstr Surg 1995;95:672-82.

5 Briant TDR, Middleton WG. The management of severe nasal septal deformities. J Otolaryngol 1985;14:120-4.

6 Kim DW, Toriumi DM. Management of posttraumatic nasal deformities: the crooked nose and the saddle nose. Facial Plast Surg Clin North Am 2004;12:111-32.

7 Clement PA, Gordts F. Standarization comitttee on objective assessment of the nasal aiway, IRS and ERS: consensus 
report on acoustic rhinometry and rhinomanometry. Rhinology 2005;43:169-79.

8 Santiago-Diez de Bonilla J, McCaffrey TV, et al. The nasal valve: a rhinomanometric evaluation of maximum nasal inspiratory flow and pressure curves. Ann Otol Rhinol Laryngol 1986;95:229-32.

9 Guillette BJ, Perry CJ. Use of nasal valve stent with anterior rhinomanometry to quantitate nasal valve obstruction. Ann Otol Rhinol Laryngol 1986;95:229-32.

10 Sulsenti G, Palma P. Tailored nasal surgery for normalization of nasal resistance. Facial Plastic Surgery 1996;12:333-45.

11 Gerlinger I, Karasz T, Somogyvari K, et al. Extracorporal septal reconstruction with polydioxanone foil. Clin Otolaryng 2007;32:462-79.
12 Hardy KL, Davis KE, Constantine RS, et al. The impact of operative time on complications after plastic surgery: a multivariate regression analysis of 1753 cases. Aesthet Surg J 2014;34:614-22.

13 Alsarraf R, Murakami CS. The saddle nose deformity. Facial Plast Surg Clin North Am 1999;7:303-10.

14 Clark JM, Cook TA. The "butterfly" graft in functional secondary rhinoplasty. Laryngoscope 2002;112:1917-25.

15 Sheen JH. Spreader graft: a method of reconstructing the roof of the middle nasal vault following rhinoplasty. Plast Reconstr Surg 1984;73:230-9.

16 Gassner HG, Friedman O, Sherris DA, et al. An alternative method of middle vault reconstruction. Arch Facial Plast Surg 2006;8:432-5.

Received: December 2, 2016 - Accepted: July 9, 2017

Address for correspondence: Giacomo Ceroni Compadretti, Imola Hospital, via Montericco 4, 40026 Imola (BO), Italy. Tel. +39 0542 662111. E-mail: g.ceronicompadretti@ausl.imola.bo.it 